$\frac{\text { ARTIGO }}{\text { dOI https://doi.org/10.22481/praxisedu.v16i41.6514 }}$

\title{
TRANSFORMANDO A SALA DE AULA UNIVERSITÁRIA: O USO DO PHOTOVOICE COMO FERRMENTA METODOLÓGICA
}

\author{
TRANFORMING THE UNIVERSITY CLASSROOM: THE USE OF PHOTOVOICE AS A \\ METHODOLOGICAL TOOL
}
TRANSFORMANDO LA CLASE UNIVERSITÁRIA: EL USO DE PHOTOVOICE COMO HERRAMIENTA METODOLÓGICA

Sandra I. Musanti

University of Texas Rio Grande Valley - Estados Unidos

Bettina Steren dos Santos

Pontifícia Universidade Católica de Rio Grande do Sul - Brasil

\begin{abstract}
Resumo: Melhorar as práticas de ensino na Educação Superior requer uma compreensão do impacto das inovações pedagógicas na aprendizagem dos estudantes, analisando as implicações teóricas e a relação entre criatividade, motivação e aprendizado. Este artigo descreve uma experiência pedagógica que integra o Photovoice, uma estratégia originalmente projetada para combinar fotografia com narração digital e participação social. Essa experiência ocorreu em um curso de mestrado online para educadores, de uma universidade no sul dos Estados Unidos. O uso do Photovoice permitiu aos alunos explorar questões de equidade, justiça social e educação através de imagens digitais como elemento mediador da aprendizagem e representação de significados. Do ponto de vista da formação de professores, esse projeto buscou modelar formas alternativas de ensino e aprendizagem, integrando as várias tecnologias que fazem parte do mundo cotidiano dos estudantes.
\end{abstract}

Palavras chave: Educação Superior; Metodologia de Ensino; Photovoice

\begin{abstract}
Improving teaching practices in higher education requires an understanding of the impact of pedagogical innovations in student learning through the analysis of the theoretical implications and the articulation of creativity, motivation and learning. This article describes a pedagogical experience that integrates the use of Photovoice, a strategy originally designed to combine photography with digital narration and social participation. This experience was implemented in an online master's course for educators at a southern university in the United States. The use of Photovoice allowed students to explore issues of equity, social justice and education through digital images as the mediating element to support the learning process and the representation of meanings. From a teacher education perspective, this project aims at modeling alternative and innovative forms of teaching and learning, integrating technologies that are part of the students' everyday world.
\end{abstract}

Keywords: Higher Education; Teaching Methodology; Photovoice. 
Resumen: Mejorar las prácticas docentes en la educación superior requiere una comprensión del impacto de las innovaciones pedagógicas en el aprendizaje de los estudiantes, analizando las implicaciones teóricas y el entrecruzamiento de la creatividad, motivación y aprendizaje. Este artículo describe una experiencia pedagógica que integra Photovoice, una estrategia originalmente diseñada para combinar la fotografía con la narración digital y la participación social. Esta experiencia tuvo lugar en un curso de maestría en línea para educadores en una universidad del sur de los Estados Unidos. El uso del Photovoice permitió que los alumnos exploraran cuestiones de equidad, justicia social y educación a través de imágenes digitales como el elemento mediador del aprendizaje y de representación de significados. Desde el punto de vista de la formación del profesorado, este proyecto tuvo como objetivo modelar formas alternativas de enseñanza y aprendizaje, integrando las diversas tecnologías que forman parte del mundo cotidiano de los estudiantes.

Palabras clave: Educación Superior; Metodología de Enseñanza; Photovoice.

\section{Introdução}

Atualmente estamos vivendo muitas transformações sociais que tem grande repercussão no contexto educacional. A formação de profissionais, na contemporaneidade está sendo repensada, já que as mudanças tecnológicas é um caminho sem volta. A preparação para o futuro deve ter como premissa o sentido que as pessoas dão as suas vidas e de que maneira elas podem trabalhar e desenvolver-se para construir uma sociedade mais justa e igualitária.

Para que esses princípios sejam levados em consideração, um dos aspectos necessários é a transformação nas salas de aula. Para pensar na sala de aula do século XXI, não podemos achar que as tecnologias digitais seriam a solução, elas podem contribuir, e muito, porém, acoplado a essas tecnologias existem uma série de fatores que podem colaborar ou atrapalhar o bom andamento do processo de ensino e aprendizagem.

Neste artigo temos como objetivo apresentar uma experiência de utilização de tecnologias digitais na sala de aula universitária de uma forma crítica, expondo como essa experiência foi organizada e quais ideias surgiram da sua análise, para contribuir com a formação de professores e consequentemente com a qualidade da sala de aula.

O ensino on-line desenvolveu-se rapidamente em muitos países (BARBOUR, 2018), e a crise mundial causada pelo COVID-19 fez mais evidente a necessidade de integrar formas efetivas de ensino virtual (ABRAMSON, 2020) especialmente no âmbito da formação de professores. Com o surgimento desses ambientes de aprendizagem, os programas de formação de docentes são colocados como o local ideal para os professores em serviço e assim construirem conhecimentos sobre o ensino em ambientes on-line. (ARCHAMBAULT; KENNEDY, 2018; MOORE-ADAMS; JONES; COHEN, 2016). Nesse contexto, melhorar as 
práticas de ensino da Educação Superior e a formação de professores exige a intersecção entre prática e pesquisa para entender o impacto das inovações pedagógicas nos estudantes, além de analisar suas implicações teóricas (PINI; AMARÉ; CERDEIRO; TERZIAN, 2017). Esse capítulo descreve uma experiência pedagógica que integra o uso de "Photovoice" ou porta-voz da foto, uma estratégia originalmente projetada para combinar fotografia, com narração digital e participação social em comunidades desfavorecidas e marginais, a fim de proporcionar-lhes um senso de ação e empoderamento.

A análise dessa prática pedagógica ajuda a identificar abordagens que permitem uma educação efetiva e equitativa, promovendo a aprendizagem autêntica baseada em projetos que geram práticas de ensino online e que integram a reflexão crítica centrada na realidade sociocultural em que os estudantes estão inseridos.

Nas últimas décadas, a pesquisa qualitativa, os métodos visuais, incluindo a fotografia, foram integrados como um meio de construir conhecimento e representar a compreensão de fenômenos sociais complexos (GIBBS; FRIESE; MANGABEIRA, 2002). No entanto, ainda há poucas pesquisas sobre os usos pedagógicos da fotografia e, mais especificamente, da imagem digital (GEWERC; ALONSO FERREIRO, 2014; SCHELL; FERGUSON, HAMOLINE; SHEA; THOMAS-MACLEAN, 2009). A literatura demonstra que os métodos visuais têm o potencial de promover o aprendizado fora e dentro da sala de aula, mas é necessária uma análise mais profunda das possibilidades desses métodos em termos do desenvolvimento de uma compreensão crítica de diversos conteúdos curriculares (SCHELL et al., 2009).

O projeto Photovoice que faz parte de um curso de mestrado on-line para educadores de uma universidade no sul dos Estados Unidos, intitulado: Os fundamentos socioculturais da educação. Esse curso é comum a vários dos programas de mestrado ministrados na Faculdade de Educação desta universidade. Por meio deste projeto, os alunos exploram através de imagens digitais - questões relacionadas à equidade, justiça social, discriminação, racismo, questões de gênero, pobreza e distribuição de recursos, entre outros tópicos possíveis. Este projeto é baseado em uma concepção sociocultural de aprendizagem e na importância de projetar oportunidades de aprendizagem que integram várias formas de representação do conhecimento. Da mesma forma, essa abordagem reconhece que, para avançar na equidade, é importante considerar a diversidade, propondo diferentes formas de acesso ao conhecimento. 


\section{Formação na pós-graduação e aprendizado on-line}

Iniciamos este apartando trazendo a definição de aprendizagem on-line:

Uma estratégia para a disseminação do conhecimento, que permite construir os conteúdos de forma colaborativa e mantê-los atualizados constantemente. Ele oferece uma imersão prática em um ambiente Web 2.0 e ambientes de simulação virtual. Permite o enriquecimento coletivo do processo de aprendizagem sem limites geográficos por meio da troca de ideias, opiniões, práticas, experiências, tudo em um só lugar, na rede (MORENO; BOLAND, 2011, p. 5).

O aprendizado on-line ocupa um lugar privilegiado como estratégia de ensino universitário no mundo, tanto na graduação quanto na pós-graduação. Embora seja uma extensão do que antes era a educação a distância, essa alternativa pedagógica exige novas formas de apresentar conhecimento, interação e avaliação da aprendizagem (DUMFOR; MILLER, 2018). Gewerc; Alonso-Ferreiro (2014, p.76) afirmam que:

As demandas que advêm da economia do conhecimento estão intrinsecamente associadas às tecnologias digitais de informação e comunicação; portanto, as instituições se sentem desafiadas e isso acontece porque mudou muito, tanto o que é considerado conhecimento valioso como a maneira pela qual é produzido e distribuído.

As novas tecnologias se cruzam e transformam as formas de interação social, impactando os espaços de aprendizagem e as formas de construção e representação do conhecimento e dessa forma contribuindo para a equidade e justiça social. Muitas investigações se concentraram em explorar e conceituar a interação social e pedagógica no campo da aprendizagem on-line, mas não houve exploração suficiente das práticas pedagógicas em relação aos conteúdos específicos e suas implicações para a aprendizagem no campo da educação universitária, graduação e pós-graduação (DUMFORD; MILLER, 2018; KENNEDY; FERDIG, 2018; WALLACE, 2010). Além disso, existe pouca pesquisa que explore como se conecta a aprendizagem on-line com temas de equidade educativa, como o acesso ao conhecimento e a tecnologia.

Montelongo e Eaton (2019) exploram as práticas pedagógicas on-line e as ferramentas tecnológicas que influenciaram a obtenção de habilidades e conhecimentos associados à competência profissional multicultural em um curso on-line para estudantes de graduação focado em justiça social e inclusão. Guthrie e McCracken (2010) investigaram como criar uma sala de aula virtual na qual diversos alunos se sintam bem-vindos para discutir e experimentar tópicos relacionados à justiça social, ação e mudança. É um estudo sobre o valor da conexão e 
da colaboração. Por meio de uma combinação de tecnologias, pedagogias e experiências no local, desenvolveram culturas virtuais que incentivam a formação de ambientes de aprendizado exigentes e motivadores, nos quais as comunicações e interações são intelectualmente transformadoras. Estas investigaciones apontam para a importância de continuar explorando as possibilidades de diferentes estratégias e usos das tecnologias disponivéis com um sentido de equidade y com a meta de modelar formas mais inclusivas de ensinar e aprender.

\section{Imagem, cultura e educação}

O desenvolvimento desde uma abordagem crítica da cultura visual requer, primeiro, o reconhecimento da importância central das imagens visuais na cultura contemporânea (KELLNER, 2008). O autor explica que a interação com as imagens e a maneira como as interpretamos é um componente básico da vida humana. No entanto, a cultura de hoje está, mais do que nunca, saturada com a imagem, o que torna a compreensão das múltiplas funções sociais muito mais importante, especialmente no campo da educação universitária que requer desenhar e implementar situações de ensino efetivas para o sujeito adulto. É claro que a disseminação e o fácil acesso à produção de imagens e vídeos digitais os tornam um meio importante, tanto como fonte de informação quanto como ferramenta para promover o conhecimento. Isso possibilita novas formas de acessar e disseminar informações, além de gerar, processar e analisá-las (GOOPY; LLOYD, 2005). Além disso, os autores explicam que a integração da imagem e do texto permite compartilhar novos conhecimentos de maneira a captar a dimensão individual, coletiva e colaborativa das práticas sociais, revelando experiências, pensamentos, emoções, relacionamentos e identidades que constituem a realidade dos participantes.

\section{Criatividade}

A criatividade não é simplesmente um entretenimento para o ócio, senão uma atitude tão vitalmente necessária quanto respirar e comer. Assim, o processo educativo nas instituições de ensino tem como finalidade (ou deveriam ter), desenvolver as potencialidades do indivíduo para que ele possa usar recursos para além da construção de conhecimentos, na busca da realização pessoal do aprendiz. É necessário pensar na formação integral do educando, ela não acontece se a expressão criadora é impedida, por isso, as instituições educativas devem estar 
preparadas para proporcionar aos estudantes um ambiente de liberdade, que permite a capacidade expressiva criadora.

Também é importante destacar que, historicamente, a criatividade era considerada como uma ação individual do sujeito. Uma pessoa tinha uma ideia criativa. Porém, nos dias atuais essa visão já está ultrapassada e devemos pensar que a criatividade deve ser desenvolvida coletivamente, em ambientes que possam promover o pensamento crítico e criativo.

A imaginação é o dom fundamental da consciência humana. (ROBINSON, 2012), a criatividade, porém, vai mais além. Ser criativo envolve fazer algo, envolve colocar a imaginação para trabalhar. Para Robinson, "a criatividade é a imaginação posta em prática". (2012, p.140). O espaço para a criatividade é um continuum em todas as etapas. Período em que se compartilham as ideias por vias práticas e visuais e ao mesmo tempo as pessoas e os grupos recebem os feedbacks.

É importante salientar que a motivação é um processo existente nos indivíduos. Para Bzuneck (2009, p. 9), "motivação, ou motivo, é aquilo que move uma pessoa ou que põe em ação ou a faz mudar de curso, a motivação tem sido entendida ora como um fator psicológico, ou conjunto de fatores, ora como um processo". Sendo assim, a motivação é pessoal, cada sujeito tem um nível de motivação em relação as suas escolhas. A busca pela realização dos objetivos pessoais está diretamente ligada aos motivos que fazem as pessoas agirem e também às questões sociais que representam os estabelecimentos dos vínculos e afetos. Portanto motivação e aprendizagem estão interligadas, pois, a motivação para aprender dá direção e intensidade à conduta humana dentro do contexto educativo.

As pessoas aprendem quando estão seguras, diante de apoio e afetividade, quando existem metas, baixo controle externo e alto reconhecimento pessoal, ou seja, conseguimos aprender realmente quando se estabelecem relações interpessoais que promovem o pensamento reflexivo.

Os alunos devem ter a possibilidade de inventar-se, de expressar seus desejos e reconhecer suas potencialidades. Necessitam a oportunidade de aprender a pensar e criar e recriar alternativas para aprender com mais significado. Aprender de maneira mais complexa e profunda, mas que tenha como ponto de partida questões relacionadas a situações reais, ou interligadas com experiências que possam unir teoria e prática.

A escola criativa educa para a mudança, para a incerteza, e para desenvolver a habilidade de aprender a aprender. O processo criativo é aquele que mobiliza qualidades que se opõem, porém são recíprocas: atividades, conotações, denotações, passividade, produtividade, 
consciência, inconsciência, e por outro lado integrando-se a esse processo, a inteligência, o pensamento, a linguagem, a percepção, a simbolização, as motivações, as emoções e toda a bagagem histórica cultural do meio de convivência.

\section{Contexto}

A experiência descrita neste artigo ocorre em uma universidade no sul do Texas, nos Estados Unidos. Essa região é conhecida como Vale do Rio Grande e estabelece a fronteira com o México. Nele, a renda salarial média anual por familia é $14 \%$ menor que a média do estado do Texas (RYABOV; MERINO, 2016). Enquanto $90 \%$ da população do Vale do Rio Grande são latinos, dos quais 50\% possuem diplomas universitários e são inferiores à taxa de graduação entre a população anglo-saxônica da região. A maioria dos estudantes dessa universidade é de origem latino-mexicana e, de acordo com um relatório da universidade, 78\% são estudantes de primeira geração. A maioria deles se define como bilíngue, com o espanhol sendo o primeiro idioma para $69 \%$ deles. No país, os latinos incrementaram o percentual de graduação em um 39\% entre 2012 e 2017 (EdEXCELENCIA.ORG, 2019). Nesta instituição, os esforços realizados resultaram em um aumento nas taxas de graduação e retenção universitária de aproximadamente 4-5\% desde 2015 (UTRGV SAIR, 2020).

A faculdade de educação dessa universidade oferece vários cursos de pós-graduação mestrado e doutorado - projetados para educadores em diferentes áreas profissionais e níveis educacionais. Os mestrados com mais alunos incluem: educação bilíngue, educação tecnológica, educação especial, educação infantil, gestão escolar e currículo e ensino. Esses mestres têm dois cursos em comum, um sobre psicologia do desenvolvimento humano e outro sobre os fundamentos socioculturais da educação. Os alunos fazem esses cursos em momentos diferentes da carreira e de acordo com cada um dos programas de estudo. A prática pedagógica descrita neste artigo faz parte da disciplina "Fundamentos Socioculturais da Educação", do mestrado. Essa disciplina dura um semestre, equivalente a 15 semanas (42 horas de aula) e foi projetado por uma das autoras deste artigo, como uma disciplina totalmente online.

De acordo com a descrição publicada no catálogo da universidade, o foco desta disciplina é identificar e analisar as forças culturais que moldam a Educação nos Estados Unidos, com ênfase nos propósitos da Educação em relação a diferentes contextos sociais e culturais; os fatores multiculturais que perpassam pela escola pública e pelo aprendizado. $\mathrm{O}$ programa dessa disciplina expande essa descrição e a define como uma exploração e análise 
das questões subjacentes às questões educacionais contemporâneas, em relação à pesquisa, teorias, políticas e práticas predominantes. Nesse sentido, é uma tentativa de entender e questionar criticamente as realidades cotidianas dos educadores sob uma perspectiva interdisciplinar no amplo contexto social, cultural, político e antropológico do país. Um elemento central da proposta é a participação ativa dos estudantes, refletindo criticamente sobre suas práticas e contexto, principalmente questionando os aspectos socioculturais e políticos que tendem a naturalizar-se na Educação. A disciplina está organizada em 6 módulos ou unidades com diferentes temas: (a) As raízes filosóficas e históricas da educação; (b) Diversidade e multiculturalismo na educação: discriminação; (c) O papel da escola na equidade educacional: classe social e pobreza; (d) Currículo e acesso ao conhecimento; (e) Reformas educacionais e políticas: o movimento de padronização; e (f) Manifestações de violência na escola e a criminalização dos jovens. Vários materiais estão incluídos para dialogar sobre esses temas. Cada unidade ou módulo inclui leituras obrigatórias, uma apresentação em vídeo do tema pelo professor e vídeos on-line que discutem ou exploram os tópicos da unidade. Além disso, a proposta pedagógica integra diferentes estratégias para promover a exploração crítica, como o desenvolvimento de um Photovoice. Essa disciplina foi ministrada por seis semestres e um total de sessenta e sete projetos de Photovoice que foram desenvolvidos individualmente pelos estudantes dos diferentes cursos de mestrado.

\section{Photovoice como estratégia pedagógica}

Photovoice é um modo de pesquisa qualitativa em Educação que utiliza imagem e narrativa e tem suas origens na pesquisa-ação participativa (STROUD, 2014). O objetivo principal é capturar as perspectivas de seus participantes sobre o mesmo fenômeno, gerando um espaço legítimo para se expressar e recuperar seu senso ativo diante de questões que afetam suas vidas (WANG, 1999). Por meio de Photovoice, suas próprias imagens e narrativas, os participantes - especialmente populações marginalizadas - podem gerar mudanças que podem ser transformadoras, à medida que exploram questões relevantes para eles e sua comunidade (WANG; BURRIS, 1997). Como estratégia metodológica, tem sido utilizada em diferentes campos da pesquisa em ciências sociais, mas principalmente na área da saúde (KURATANI; LAI, 2011). Essa estratégia surge como um romance fotográfico e tem suas raízes mais profundas nos pressupostos de Paulo Freire (2011) e na educação emancipatória, mas também está ancorada na pedagogia feminista e na fotografia documental (WANG; BURRIS, 1994). A 
ideia central que passa por essa proposta é a ênfase na participação da comunidade para fins de ação social. A partir de uma perspectiva emancipatória, os participantes começam olhando sua realidade através da câmera, coletando informações na forma de imagens que representam sua realidade e seus problemas a partir de sua perspectiva. Essas imagens são ressignificadas e reconstruídas através do diálogo e da narrativa (KURATANI; LAI, 2011; WANG; BURRIS, 1994).Seguindo a perspectiva da teoria feminista, ninguém está melhor posicionado para estudar e entender a realidade de um grupo ou comunidade do que seus próprios membros (STRACK; MAGILL; MCDONAGH, 2004). Embora as possibilidades de ação social sejam limitadas, como estratégia pedagógica, ela tem o potencial de se tornar uma atividade focada nos estudantes e em seus interesses, enquanto construtores de um olhar crítico sobre a realidade que os cerca. Diferentes estudos documentam o uso de Photovoice para fins pedagógicos em diferentes áreas de conteúdo, tanto nos Estados Unidos quanto em outros países (DOVAL; MARTINEZ-FIGUEIRA; RAPOSO， 2013; GEWERC; ALONSO-FERREIRO， 2014; STROUD, 2014; SCHELL at al., 2009).

\section{Descrição do projeto}

Inicialmente os estudantes devem identificar, individualmente, um tema em conexão com os tópicos discutidos em sala de aula, interrogar algum aspecto da realidade social e cultural que os cerca em interseção com Educação na comunidade, incluindo questões relacionadas à discriminação de raça, gênero, orientação sexual, nacionalidade ou origem, estratificação social, violência social, pobreza, recursos e saúde, entre outras possíveis dimensões de análise discutidas na classe. Ressalta-se que, na escolha do tema, considerem o que afeta sua comunidade, entendendo a comunidade em termos amplos (escola, bairro, cidade, região, estado ou país). Eles são convidados a elaborar um esquema ou rascunho do projeto, pensando em como comunicar a importância do tópico de uma maneira que seja entendido e que gere conscientização em um amplo público. Isso ocorre porque, em geral, os alunos tendem a criar projetos com uma audiência limitada ao professor e, em alguns casos, aos colegas de classe. Os alunos desenvolvem esse projeto no meio do semestre e, depois de estudar temas como cultura, socialização e educação, o significado da equidade e igualdade educacional, as teorias sociológicas, como o funcionalismo e a teoria do conflito social, para explicar os diferentes conceitos em relação ao lugar e ao papel da escola e da educação pública na sociedade. 
Antes de desenvolver o projeto, cada estudante compartilha seu rascunho em um fórum de discussão no qual recebe feedback de seus colegas e do professor. Essa etapa é importante porque implica receber a aprovação do tema do projeto, principalmente considerando a adequação do assunto, os objetivos da disciplina, as atividades e os argumentos construídos. Os feedbacks são utilizados para melhorar sua proposta e levá-la adiante.

Nesse projeto, eles devem ilustrar o tema escolhido através de imagens digitais (total de 8 a 10 fotos). O projeto exige que a maioria das imagens seja de autoria própria, com um mínimo de imagens recuperadas de diferentes fontes, como Internet ou bancos de imagens. Ou seja, os alunos devem consultar e ler sobre o assunto e, em seguida, usar esse conhecimento e seleção de ideias-chave para selecionar imagens representativas. Um aspecto crítico deste projeto é que os alunos devem refletir sobre as imagens, ou seja, decidir quais imagens podem obter usando seu telefone celular ou outro tipo de câmera para representar como o assunto explorado afeta sua comunidade. A proposta é que o produto final (vídeo) permita informar públicos variados e aumentar a conscientização sobre a relevância do problema.

Cada imagem deve incluir uma legenda que defina sinteticamente o conteúdo e o significado da imagem em relação ao tema escolhido. É importante que os alunos entendam que o texto escrito em cada imagem deve ser mínimo (como as legendas dos jornais e fotos dos jornais), mas que consiga expressar a ideia central de que a imagem selecionada tenta comunicar. Em geral, os alunos têm dificuldade em deixar de lado a tendência de confiar apenas na palavra escrita para representar suas ideias. Muitas vezes, as apresentações tem muito texto e prejudicam a interpretação das imagens.

Outro aspecto importante é a preparação do vídeo. Nas instruções para o desenvolvimento do projeto, os estudantes têm liberdade para usar diferentes tipos de software para criar um vídeo que integra imagem e som. Ou seja, os alunos utilizam os recursos tecnológicos à sua disposição, como Powerpoint, Camtasia, Imovie, Vimeo ou outro software similar que permite a construção de um vídeo integrando imagens, texto e som.

O produto final deve integrar essas três representações dos temas escolhidos, explicando a mensagem mais importante. Quando o vídeo é concluído, cada aluno envia o arquivo para um fórum de discussão. Esta etapa é importante porque possibilita compartilhar com seus colegas e professores o seu trabalho e o tema escolhido para criar uma consciência social sobre sua importância.

Um requisito importante deste projeto é que os alunos participem do fórum assistindo aos vídeos publicados e reagindo aos temas propostos de maneira construtiva. Cada aluno deve 
participar do processo de feedback, olhando para cada photovoice e escolhendo, pelo menos, três projetos para comentar sobre o conteúdo. Neste fórum de discussão, eles também recebem comentários do professor e, em seguida, individualmente a avaliação final.

É importante notar que, na preparação para a elaboração do projeto, o professor organizou uma reunião síncrona por meio da plataforma Blackboard usada pela universidade. Durante esta reunião, foram explicadas as ideias centrais de Photovoice e compartilhados exemplos e materiais teóricos disponíveis on-line, como: Desenvolvimento de um Photovoice em sua comunidade, um sitio web onde os estudantes podem encontrar uma explicação detalhada do uso de essa ferramenta, bem como exemplos variados.

\section{Análise da proposta}

Essa experiência de ensino foi uma oportunidade de aprendizado muito significativa para os alunos e o docente. Os estudantes que participaram dessa tarefa tiveram uma visão única da complexidade da educação como um fenômeno sociocultural e também lhes deram a oportunidade de explorar ideias e criar seu próprio significado através da aplicação do conhecimento do curso e da participação ativa no processo de aprendizagem. Para o professor, foi uma oportunidade de explorar o poder da imagem na construção e representação da compreensão conceitual, bem como na reflexão crítica dos alunos. Inicialmente, a experiência exigia o esforço de sair da zona de conforto gerada pela palavra escrita em termos da forma do ato de ensinar e como um meio de avaliar a aprendizagem. Isso também implicava uma aproximação às formas de comunicação e usos digitais dos jovens, permitindo que o professor também conhecesse novas ferramentas. Em muitos casos, e com o passar dos semestres, os estudantes começaram a usar menos Powerpoint ou Prezi e mais outras ferramentas para produzir e / ou publicar os vídeos do orador. Por exemplo, os alunos começaram a postar vídeos no YouTube, para que seus vídeos só fossem acessíveis através do compartilhamento do link. Alguns usaram o Mybrainshark.com, que facilita a produção de vídeos postados online. Outras alternativas para a produção de vídeos incluem o Voice.adobe.com, que é uma ferramenta gratuita para a produção de histórias digitais e o Vimeo.com, que permite o compartilhamento de vídeos on-line. Alguns alunos ainda preferem produzir a apresentação usando o Powerpoint e depois converter o arquivo em vídeo com diferentes formatos. A maioria dessas estratégias e ferramentas, com exceção do YouTube, Powerpoint e Prezi, era desconhecida do docente, mas 
permitiu o aprendizado cooperativo com oportunidades para que os alunos com mais conhecimentos pudessem compartilhá-los.

Nos casos em que as imagens incluíam elementos de identificação, protegidos pelos regulamentos de confidencialidade em vigor na instituição e no país, por exemplo, em relação às crianças, foram levados em consideração. Por exemplo, uma aluna que criou um photovoice com uma coleção de fotos tiradas por seus alunos do ensino médio ao atravessar a fronteira México-Estados Unidos todos os dias para ir à escola. O photovoice da foto ilustrou as dificuldades, perigos e esforços de muitos adolescentes mexicanos que tentavam obter seu diploma do ensino médio nos Estados Unidos. Este projeto foi posteriormente expandido por essa aluna por meio de uma investigação que incluiu entrevistas com as alunas narrando essa experiência cotidiana e suas emoções e percepções.

Uma breve análise dos temas predominantes no photovoice produzidos pelos alunos ao longo dos seis semestres considerados neste artigo gera evidências sobre a realidade social e cultural da região e permite inferir o potencial desse tipo de atividades para abrir espaços para reflexão crítica sobre sua própria realidade, criando mais oportunidades para uma educação que gere consciência e abra caminhos para mudanças sociais e educacionais.

A maioria dos projetos incluiu questões relacionadas à pobreza (9) com questões de equidade associadas à estratificação social (3) e segregação (2), com as desvantagens impostas às minorias, especialmente latinos imigrantes (7), e questões de desigualdade na distribuição de recursos e fundos que afetam desproporcionalmente os setores mais desfavorecidos (6).

Embora os dados não permitam inferências definitivas, é possível dizer que o problema da pobreza na região obscurece e oculta questões de discriminação racial que ainda são muito válidas, por exemplo, a falta de acesso de crianças cujo primeiro idioma é o espanhol. Programas de ensino bilíngue de qualidade. Apenas oito estudantes desenvolveram projetos que discutiam a falta de acesso e / ou a falta de recursos disponíveis para desenvolver programas educacionais de qualidade, apenas um discutia a discriminação em termos de acesso a programas de educação bilíngue. Outros projetos abordaram questões como acesso à tecnologia e implicações educacionais (5), questões de educação e saúde como obesidade e diabetes, alta incidência na região e também associadas à pobreza (5), a importância do papel dos pais nas realizações educacionais das crianças (envolvimento dos pais e desempenho dos alunos), uma área de pesquisa altamente desenvolvida no país e com repercussões diretas no nível escolar (3). Um tema com alta incidência entre os projetos é a questão da violência social e da escola, especificamente na sua manifestação através do bullying (7). 


\section{A imagem digital como estratégia pedagógica}

Pesquisas sugerem que o uso de estratégias que integram imagens e elementos visuais de maneiras variadas promove o aprendizado assim como o desenvolvimento da criatividade. Isso significa que os alunos precisam aprender visualmente e os professores precisam aprender a ensinar visualmente. É importante que professores de diferentes níveis de ensino comecem a usar de maneira mais eficaz os elementos e práticas que fazem parte do cotidiano e da cultura dos alunos, a imagem é um deles (STOKES, 2002). Nesse campo, podemos nos beneficiar das contribuições que advêm da área de alfabetização visual e educação como empoderamento de uma perspectiva freiriana (STOKES, 2002; STRACK et al., 2004). A identificação de imagens que "capturam" o significado da realidade dos alunos os posiciona como participantes ativos na compreensão dos problemas que afetam sua comunidade, gerando um produto que pode ser compartilhado e que pode se tornar o mediador da construção. de um significado coletivo e, em alguns casos, como um elemento de mudança. Nesse sentido, vários alunos expressaram sua intenção de usar o photovoice em sua escola ou local de trabalho como motivador de mudança ou como estratégia para gerar uma reflexão crítica e informada sobre certos fenômenos: bullying, crianças que vivem na pobreza, nutrição e aprendizado, entre outros. Constatou-se que a partir dessa prática, o espaço para desenvolver a criatividade e o pensamento crítico dos estudantes foi mais explorado e propicio, já que as imagens falavam por si só e levava os estudantes a dialogar a partir de informações concretas. As estratégias didático-pedagógicas que envolvam os estudantes em todo o processo de ensino e aprendizagem, podem ajudar para o protagonismo e na construção de seus saberes que contribuirão para vida profissional.

Muitos dos estudantes eram de famílias de baixa renda, no entanto, a partir dessa atividade eles começaram a dialogar de forma mais explicita sobre a realidade que eles viviam, naturalizando aspectos que anteriormente eram tabus na sala de aula. Esse projeto permitiu ver como a pobreza influencia a aprendizagem dos estudantes.

Esses tipos de projetos permitem a apropriação ativa de imagens através das quais os alunos podem representar e reconstruir criticamente a realidade, compartilhá-las e refletir sobre essas diferentes experiências através de diferentes formas de interação e comunicação estabelecida em sala de aula (DOVAL et al., 2013). Com a expansão de novas tecnologias, fica claro que o uso de imagens se tornará mais frequente e acessível.

De acordo com outras pesquisas, pode-se afirmar que o desenvolvimento e a implementação dessa estratégia pedagógica influenciaram não apenas a possibilidade de 
expandir a compreensão crítica de múltiplos fenômenos socioeducativos, mas também de explorar a imagem como estratégia de coleta de informações, integrando imagem e texto digital. Isso abre espaços para formas de construção do conhecimento que integram a cultura visual atual (GOOPY; LLOYD, 2005). Significava um espaço para explorar as possibilidades e os desafios de incorporar a fotografia em sua prática pedagógica e os benefícios de combinar imagem e teoria social no contexto do ensino on-line, essa prática deixou clara as possibilidades de promover a criatividade dos estudantes em situação de vulnerabilidade.

\section{Conclusões e implicações para a prática}

Ao avançar as formas culturais do novo milênio, educadores e especialmente aqueles que trabalham com formação de professores, devemos interrogar nossas práticas e espaços abertos que exploram a cultura digital como uma forma de expressão e construção de conhecimento no ambiente escolar. Isso requer a integração do que alguns autores chamam de alfabetização visual crítica e a capacidade de ler e contextualizar diversas representações visuais e gráficas (KELLNER, 2008). A exploração de práticas participativas e comunitárias, como o Photovoice, pode aprofundar o compromisso social dos estudantes de pós-graduação, na medida em que se constata que a criatividade dos estudantes é promovida, motivando-os mais a aprender. Isso é especialmente importante quando se trata de formar educadores que podem se tornar o que Giroux (1990) conceituou como professor intelectual transformador. Nesse sentido, uma atividade que proporciona o diálogo e a abertura para expor seus pensamentos ajuda a desenvolver a criatividade, aspecto esse fundamental para que os estudantes busquem sentido na sua aprendizagem.

A implementação desta prática deixou importantes lições e aspectos que poderiam ser mais explorados:

- Estratégias como o Photovoice abre as portas para os professores construírem uma visão crítica da realidade social e educacional, criando pontes significativas entre teoria e prática.

- O Photovoice é uma ferramenta pedagógica que permite a integração de formas de conhecer e interpretar a realidade da cultura digital.

- No caso dessa experiência, permitiu modelagem para professores que estavam concluindo o mestrado, uma estratégia que inclui a tecnologia para produzir conhecimento, entender a realidade e conectá-la à teoria, com a expectativa de integrá-la em suas aulas e ao 
trabalhar com seus alunos, possibilitar experiências semelhantes de análise da realidade social em diferentes níveis de ensino.

- Um dos resultados mais destacados é uma maior conscientização da realidade educacional e um compromisso com o contexto social, questionando o que é naturalizado. Por exemplo, em muitos casos, os alunos concluem o projeto e a turma "perceber" a realidade que seus estudantes estão vivendo, o impacto e a injustiça social inerentes à atual política de padronização em vigor nos Estados Unidos e especialmente no estado do Texas.

- Para docentes encarregados de ministrar cursos on-line de conteúdos semelhante, é importante deixar a zona de conforto gerada pela palavra escrita, tão predominante na educação a distância tradicional, e explorar novas formas de ensinar e aprender de forma assíncrona e significativa.

Photovoice é uma ferramenta potente para poder ampliar o processo criativo no contexto da sala de aula. A possibilidade de espaços de diálogo para a aprendizagem é fundamental para poder se colocar no lugar do outro e se tornar uma pessoa empática, características essas fundamentais na contemporaneidade.

Em termos de implicações para essa disciplina, essa análise, embora limitada, permite ver que esse projeto requer um contexto colaborativo e participativo. $\mathrm{O}$ ensino online impõe o desafio de gerar estratégias para promover espaços de colaboração e cooperação entre os estudantes, gerando discussões significativas e promovendo a reflexão crítica sobre fenômenos complexos. Com base na análise das possibilidades e limitações que essa prática mostrou, nas próximas edições do curso o projeto será elaborado em grupos, com ênfase na interação dos pares para decidir sobre um tópico relevante para a comunidade, elaborar uma proposta de ação e discutir as diferentes imagens que representam o fenômeno e seu significado socioeducativo.

\section{REFERÊNCIAS}

ABRAMSON, Ashley. Enhancing online learning. COVID 19 Special Report. Monitor on Psychology, 51(4), p. 56-57, 2020.

ARCHAMBAULT, Leanna; KENNEDY, Kathryn. Teacher Preparation for K-12 Online and Blended Learning. In: Kennedy, Kathryn and Richard Ferdig (Eds) Handbook of Research on K-12 Online and Blended Learning (Second Edition). (221-246). Pittsburgh, PA: Carnegie Mellon University: ETC Press. 2018.

BARBOUR, Michael. A History of K-12 Distance, Online, and Blended Learning Worldwide. En Kennedy, Kathryn and Richard Ferdig(Eds) Handbook of Research on K- 
12 Online and Blended Learning (Second Edition).(21-40). Pittsburgh, PA: Carnegie Mellon University: ETC Press. 2018.

BZUNECK, José Aloyseo. A motivação do estudante: aspectos introdutórios. In:

BORUCHOVITCH, Evely.; BZUNECK, José Aloyseo. (Org.). A motivação do estudante: contribuições da psicologia contemporânea. 4. ed. Petrópolis: Vozes, 2009.

DOVAL, Maria Isael; MARTINEZ-FIGUEIRA, Maria Esther.; RAPOSO, Manuela. La voz de sus ojos: la participación de los escolares mediante Photovoice. Revista de Investigación en Educación, 11(3), p.150-171, Disponível en: http://webs.uvigo.es/reined/, 2013.

DUMFORD, Amber D.; MILLER, Angie L. Online Learning in Higher Education: Exploring Advantages and Disadvantages for Engagement. Journal of computing in higher education 30 (3), p. 452-465, 2018.

EdEXCELENCIA.ORG. Latinos in Higher Education. Compilation of Fast Facts. Disponível em: https://www.edexcelencia.org/media/946, 2019.

FREIRE, Paulo. Pedagogia da autonomia: saberes necessários à prática educativa. 43. ed. São Paulo: Paz e Terra, 2011.

GEWERC, Adriana; ALONSO-FERREIRO, Almudena. Enriquecimiento de la enseñanza con tecnologías. La visión del alumnado. Revista Latinoamericana de Tecnología Educativa, 13(1), p. 75-87. 2014.

GIBBS, Graham. R.; FRIESE, Susanne., MANGABEIRA, Wilma. C. The use of new technology in qualitative research. Forum: Qualitative Social Research, 3(2). 2002. Disponível em: http://www.qualitative-research.net/index.php/fqs/article/view/847

GIROUX, Henry. Los profesores como intelectuales. Barcelona, España: Paidós. 1990.

GOOPY, Suzanne. Elisabeth; LLOYD, David. Documenting the human condition in everyday culture: Finding a partnership between ethnography and photo-documentary. International Journal of the Humanities, 3(5), p. 33-38, 2005.

GUTHRIE, Kathy L, and Holly MCCRACKEN. Teaching and Learning Social Justice through Online Service-Learning Courses. International review of research in open and distance learning 11 (3), p. 78-94. 2010.

KELLNER, Douglas. Critical Perspectives on Visual Imagery in Media and Cyberculture. Disponível em: https://pages.gseis.ucla.edu/faculty/kellner/ed270/VISUALLITcritical.htm., 2008.

KENNEDY, Kathryn; FERDIG, Richard. (Eds). Handbook of Research on K-12 Online and Blended Learning (Second Edition). Pittsburgh, PA: Carnegie Mellon University: ETC Press. 2018

KURATANI, Darrah. G; LAI, Elaine. TEAM Lab - Photovoice Literature Review. University of Southern California. Disponível em: https://cpb-us- 
e1.wpmucdn.com/sites.usc.edu/dist/0/198/files/2018/08/Photovoice-Literature-ReviewFINAL-22ltfmn.pdf, 2011.

MONTELONGO, Ricardo; EATON, Paul William. Online Learning for Social Justice and Inclusion: The Role of Technological Tools in Graduate Student Learning. The international journal of information and learning technology 37(1/2), p. 33-45. 2019

MORENO, Ana Maria; BOLAND, Philippe. El aprendizaje en línea. Entre/N TIC. Disponível em: http://revista.enredo.org/spip.php?article116, 2011.

MOORE-ADAMS, Brianne L,; JONES, W. Monty; COHEN, Jonathan. Learning to Teach Online: A Systematic Review of the Literature on K-12 Teacher Preparation for Teaching Online. Distance education 37(3), p. 333-348, 2016.

PINI, Monica. E., AMARÉ, M., CERDEIRO, C. E TERZIAN, C. Mundo escolar y mundo juvenil. La escuela frente al desafío de derribar muros. En M. E. Pini, E. Valente \& M. Landau (Eds.), Nuevas y viejas tecnologías para el aula. Prácticas y reflexiones pedagógicas. Convergencia y enseñanza. (pp. 17-42). Buenos Aires: Aique. 2017.

ROBINSON, Ken. Libertando o poder criativo: a chave para o crescimento pessoal e das organizações. São Paulo: HSM Editora, 2012.

RYABOV, Igor; MERINO, Stephen M. Recent Demographic Change in the Rio Grande Valley of Texas: The Importance of Domestic Migration. Sociology Faculty Publications and Presentations. 9. 2016. Disponível em: https://scholarworks.utrgv.edu/soc_fac/9

SCHELL, Kara; FERGUSON, Alana; HAMOLINE, Rita; SHEA, Jeniffer; THOMASMACLEAN, Roanne. Photovoice as a Teaching Tool: Learning by Doing with Visual Methods. International Journal of Teaching and Learning in Higher Education, 21(3), p. 340-352, 2009.

STOKES, Suzanne. Visual literacy in teaching \& learning: A literature perspective. Electronic Journal for the Integration of Technology in Education. 1 (1), p. 10-19, 2002.

STRACK, Robert, W.; MAGILL, Cathleen; MCDONAGH, Kara. Engaging youth through photovoice. Health Promotion Practice, 5(1), p. 49-58, 2004.

STROUD, Michael. Photovoice as a Pedagogical Tool: Student Engagement in Undergraduate Introductory Chemistry for Nonscience Majors. Journal of College Science Teaching, 43(5), p. 98-107, 2014.

UTRGV SAIR, Office of Strategic Analysis and Institutional Reporting. 2020.

WALLACE, Raven. M. Online Learning in Higher Education: a review of research on interactions among teachers and students. Education, Communication \& Information, 3(2), p. 241-280, 2010.

WANG, Caroline. Photo Voice: A participatory action research strategy applied to women's health. Journal of Women's Health, 8(2), p. 185-192, 1999. 
WANG, Caroline; BURRIS, Marry. Photovoice: Concept, methodology, and use for participatory needs assessment. Health Education \& Behavior, 24, p. 369-387, 1997.

WANG, Caroline; BURRIS, Mary. Empowerment through photo novella: Portraits of participation. Health Education Quarterly, 21, p. 171-186, 1994.

\section{SOBRE AS AUTORAS:}

\section{Sandra I. Musanti}

Ph.D. Educational Thought and Sociocultural Studies, Doctora em Filosofia, University of New Mexico (UNM) - United States. Trabalha University of Texas Río Grande Valley (UTRGV) United States. Doctorate in Education in Curriculum and Instruction. Grupo de Pesquisa Formação docente bilingue, colaboração docente, translingualismo e educação, rol de cultura e linguajem na formação de professores. E-mail: sandra.musanti@utrgv.edu

iD http://orcid.org/0000-0002-1294-4434

\section{Bettina Steren dos Santos}

Professora Visitante na Faculdade de Educação/Universidade de Barcelona (UB) - Espanha. Pós-doutorado em Educação pela Univeristy of Texas at Austin (UT) - United States. Doutora em Psicologia Evolutiva e da Educação pela Universidade de Barcelona (UB) - Espanha. Trabalha na Pontifícia Universidade Católica do Rio Grande do Sul (PUCRS) - Brasil. Programa de Pós-Graduação em Educação; Grupo de Pesquisa Processos Motivacionais em Contextos Educativos (PROMOT); Bolsista de Produtividade 1D/CPNq. E-mail: bettina@pucrs.br

iD http://orcid.org/0000-0002-5595-232X 